\title{
Experimental Study on the Hydrodynamic Influence of River Flow Confluences to the Open Channel Stage-Discharge Relationship
}

\author{
Xiekang Wang ${ }^{1}$, Haizhou Wang ${ }^{1}$, Xufeng Yan ${ }^{1,2}$, Xingnian Liu ${ }^{1}$ and Huan-Feng Duan ${ }^{2, *}$ \\ 1 State Key Laboratory of Hydraulics and Mountain River Engineering, Sichuan University, Chengdu \\ 610065, China \\ 2 Department of Civil and Environmental Engineering, The Hong Kong Polytechnic University, Hong Kong \\ SAR, China \\ * Correspondence: hf.duan@polyu.edu.hk; Tel.: +85-2-3400-8449
}

\begin{abstract}
An accurate assessment of the stage-discharge relationship in open channel flows is necessary and important to the design and management of hydraulic structures and engineering in practical hydrosystems such as rivers and streams. While the flow structures and patterns at open channel junctions are interesting and have been widely studied in the literature, this paper focuses further on the effect of flow junctions on stage-discharge relationship at mountain river confluences. In this study, both the flume and physical model experiments are designed and performed carefully to test and analyze the complex flow structures and characteristics at river confluences with different configurations and hydraulic conditions. The impacts of the flow junctions on the traditional stage-discharge relationship are analyzed in this study. The results of this study are discussed in the paper for the understanding of flow structures at flow junctions and the design and management of hydraulic structures in river engineering.
\end{abstract}

Keywords: river confluence; stage-discharge relationship; hydrodynamic influence; backwater; flow separation

\section{Introduction}

Flow junctions commonly exist in practical open channel hydrosystems such as natural rivers and streams with confluences, especially in the mountain area watersheds in Southwest China [1]. It has been widely demonstrated in previous researches and engineering experiences that the behaviors and characteristics of flows at river confluence zones are much more distinctive and complicated than in the regular and single channel (e.g. [2, 3]). For illustration, the influence of flow confluences on the flow structure and behaviors at junctions is sketched in Fig. 1 [4], which shows clearly the complex hydrodynamic process and response of mixing flows at the junction such as sediment transport and coherent flow structure. From the practical point of view, it is important to investigate the influences of channel complexities such as river confluences on the flow structures and patterns, in order to better design and management of hydraulic structures and associates in river engineering. From the scientific point of view, it is necessary to understand the hydrodynamic mechanisms of mixing flows at complex river confluences, in order to facilitate the development of theory and models in open channel hydraulics such as modeling of turbulence and mixing layers. Therefore, investigation of the junction flow characteristics at river confluences may bring great interests and benefits to the theory and practice of river hydraulics and hydrodynamics. 


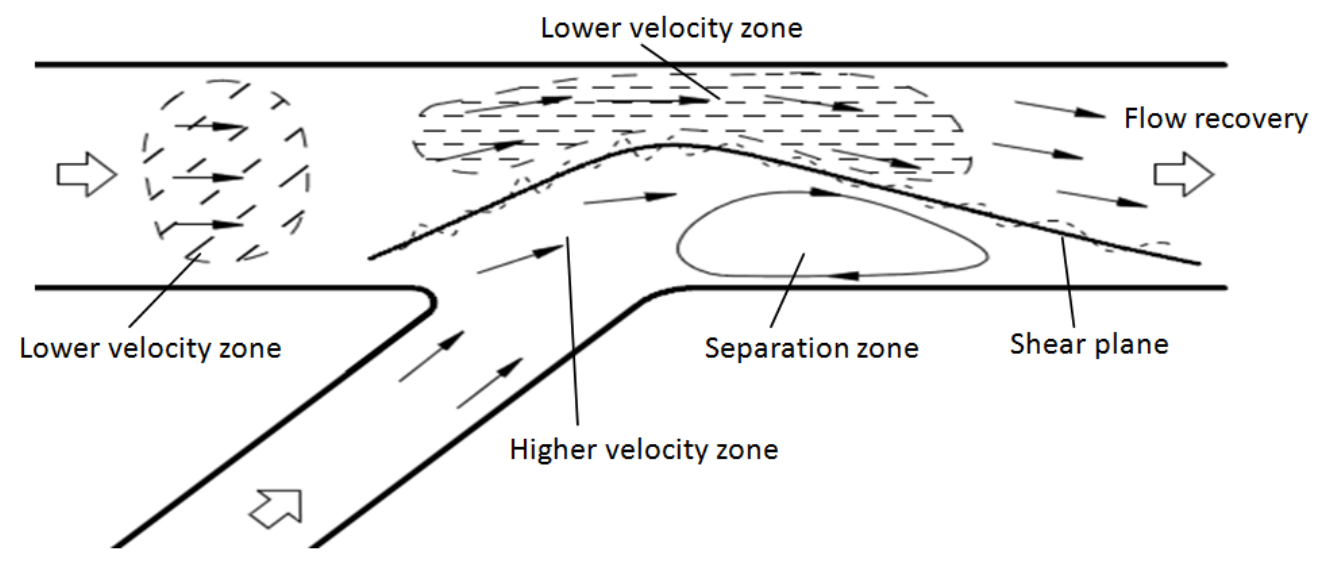

Figure 1. Typical sketch of flow structures at river confluence (adapted from [4])

Many previous numerical and experimental studies have focused on the hydrodynamic behaviors and responses of open channel flows with confluences, such as flow structure and pattern (backwater, separation and circulation), turbulence and coherent structure (resistance and shear stress), and system responses (flooding and discharge influences). With regard to the flow structure and pattern at channel flow confluences, Taylor [5] first discussed the influence of depth changes on the open channel flows in a rectangular open channel junction. Webber and Greated [6] proposed a theoretical flow pattern according to the experimental observations in that study. Thereafter, the impacts of flow confluences at different channel junctions on the flow pattern and structures were widely investigated through various numerical and experimental studies in the past decades (e.g., [7-20]). All the results of these studies have shown and evidenced that the flow junctions with different properties (e.g., size ratio, angle and water depth change due to concordant/discordant bed) could affect greatly the characteristics of the flow pattern and structures and thus the hydrodynamic responses at the confluence zone, with indicating that the effects of the flow junctions and characteristics have to be considered and included in the hydraulic modeling process so as to obtain better physical interpretations and accurate numerical predictions.

With understanding the importance and influence of the confluence junctions to the modeling and process of flow pattern and structures, many researches have put forward efforts in the quantifying and modeling of the turbulence behaviors the flow junctions. For example, the significant impact of bed discordance on the flow acceleration behind the confluence was observed and studied in [21-24], in which the physical mechanism and process of the formed turbulence due to the flow confluence at channel junction were analyzed and explained based on their obtained experimental data and numerical results. The studies of [2, 23 and 24] have also demonstrated the characteristics of turbulence and coherent turbulent structures within the shear layer through a field system study of three stream confluences in east central Illinois. In addition, Yang et al. [25] analyzed further the influence of turbulence characteristics at confluence junctions on the open-channel confluence flows based on numerical and experimental studies. However, it can be concluded from these previous studies that the formed turbulent flow behaviors and characteristics at flow junctions could not be fully understood and generally represented by current turbulence models and theory, which is worthy of further investigations.

Regarding to the system responses corresponding to the influences of flow confluences, the study of [26] evidenced that flooding in streams upstream of the confluence junction was more frequent than that in streams downstream of the junction based on the field observations in the middle Yellow River in China. Their results and analysis indicated that for a fixed total discharge from all the mainstream and tributary rivers, the water levels at the junction could be very different due to the different allocations of the discharges among mainstream and tributary rivers. These results and findings were confirmed thereafter by numerical simulations in [27]. Furthermore, an improved stage-discharge method was proposed in [28] by considering the momentum transfer in 
compound channel, so that the influence of the flow junction on the discharge responses could be included. In that study, the transport of transverse momentums between the main and tributary rivers was shown obviously at river confluence zone, which actually attributes to the flow backwater at the upper stream of the flow junction and the flow separation and compression (or accumulation) at the downstream of the flow junction. From this perspective, understanding and investigating the influence of flow junctions on the open channel flows may have great practical significance such as flooding control and management in river engineering.

Despite these many previous studies on the importance and influence of the flow junctions to open channel flows shown above, very few studies so far have systematically investigated the stagedischarge relationship at flow confluences. Particularly, among these few previous preliminary studies, Wilson et al. ([29]) discussed the effects of turbulence model on the stage-discharge changes in compound channel flows based on numerical method. Liao and Knight ([30]) pointed out the significant impact of secondary flows on the stage-discharge relationship in rectangular compound channels. Kean and Smith ([31]) presented a method of stage-discharge relationships in gravel-bed channel through considering the changed gravel roughness and relative coefficient. However, most of the current studies focused on the open channels with regular or uniform configurations of transverse and/or longitudinal sections, and the characteristics of natural river confluences such as complex mountain river networks have not yet been systematically investigated in the literature, which is the scope of this study.

This paper first examines the detailed flow characteristics at different confluence junctions through the laboratory flume experiments, which were conducted in the State Key Laboratory of Hydraulics and Mountain River Engineering at Sichuan University, China, with the aim to verify and confirm the results and findings of previous studies in terms of the flow structures and patterns at flow junctions. Meanwhile, the influence of flow junction properties to the stage-discharge relationship is analyzed quantitatively based on the extensive experimental data in this study, in order to evaluate the validity of traditional stage-discharge relationship for expressing the hydrodynamic effect of river junctions on confluence flows. Finally, the results of this study are discussed for the practical implications and significance to river hydraulics and engineering.

\section{Materials and Methods}

To conduct systematic analysis of junction flows at the river confluence, two sets of experimental testing program are designed and adopted for this study, which were constructed in the State Key Laboratory of Hydraulics and Mountain River Engineering at Sichuan University, China. Specifically, the laboratory discharge flume channel with regular cross-sectional shape is used for testing the hydraulic characteristics at the confluence junction under different conditions, including the velocity field and water level distributions. The results are used to verify and confirm the results and findings of previous relevant studies in this field, and meanwhile, to further understand the basic physics and process of junction flows at the confluence under well-controlled system conditions. Thereafter, two physical models are designed based on the prototypes of different mountain area river confluences in Southwest China, in order to obtain additional data measurement results under more realistic conditions to validate the results of regular tests and measurements in the laboratory, and thus to establish and analyze the stage-discharge relationship of junction flow at confluences. For clarity, the detailed setups and testing plans of these experiments are presented in the followings.

\subsection{Setup and measurement of laboratory flume experiments}

The flume experiment was carried out at a 30 degree angle branched confluence flume in the laboratory. The total flowrate of the flume channel is $0.122 \mathrm{~m}^{3} / \mathrm{s}$, in which the discharges from the main and tributary flumes are $0.069 \mathrm{~m}^{3} / \mathrm{s}$ and $0.053 \mathrm{~m}^{3} / \mathrm{s}$ respectively. The flume geometric parameters are listed in Table 1. Figure 2 shows the plane arrangement of flume experimental system, which shows the flow velocity measuring points and experimental test scenarios. The measurement distance is about $0.5 \mathrm{~cm}$ between two adjacent points in each vertical measuring line, with the measured velocity components used to analyze the non-uniformity of velocity distribution in the confluence 
zone. In this study, the velocity measurements were obtained by using an Acoustic Doppler Velocimeter (ADV, Sonteck) operating at $16 \mathrm{M} \mathrm{Hz}$ acoustic frequency at different locations of the flume bed. The sampling rate of the ADV is $50 \mathrm{~Hz}$ and the duration of the measurements for every position was set at $60 \mathrm{~s}$. In each vertical line, the detection result by using the 3D down-looking probe ADV was used to represent the average value for the $10 \mathrm{~cm}$ wide distance region $( \pm 5 \mathrm{~cm}$ from the line) along the transverse direction from the channel wall with a small sampling volume. As a result, in total 10 vertical measuring lines are planned for each transverse section (i.e., $\mathrm{y}^{*}=0.05 \sim 0.95$ in Fig. 2 ), which are denoted as lines $5 \# \sim 95 \#$ in the following study. In addition, the water level at each location was also obtained by means of a ruler with measurement precision of $0.5 \mathrm{~mm}$.
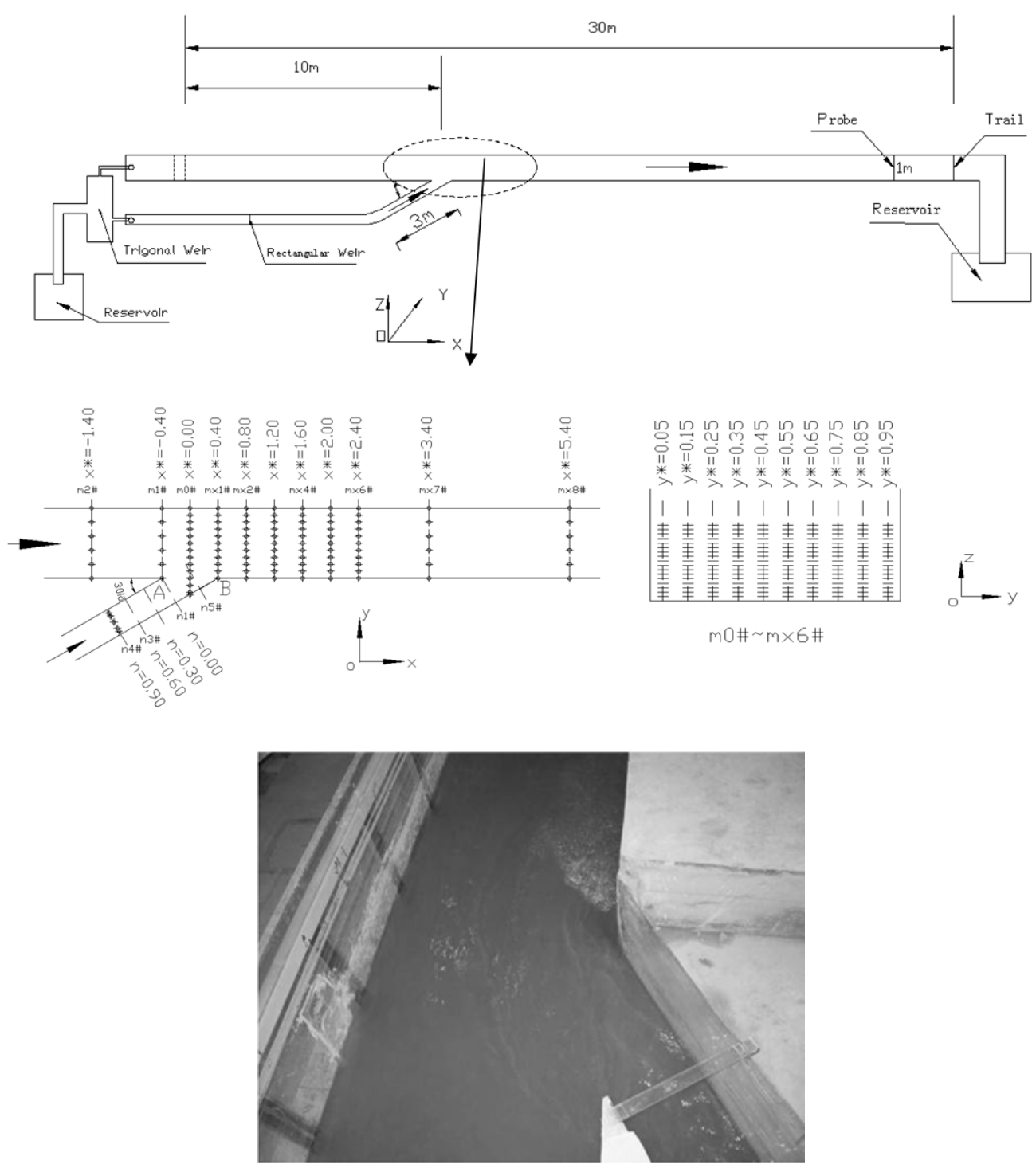

Figure 2. Schematic and test scenario of flume experimental system

Table 1 Flow conditions and test parameters of the flume experiment

\begin{tabular}{c|c|c|c|c|c|c}
\hline \multirow{2}{*}{$\begin{array}{c}\text { Main flume } \\
\text { discharge }\left(\mathrm{m}^{3} / \mathrm{s}\right)\end{array}$} & $\begin{array}{c}\text { Tributary flume } \\
\text { discharge }\left(\mathrm{m}^{3} / \mathrm{s}\right)\end{array}$ & $\begin{array}{c}\text { Total discharge } \\
\left(\mathrm{m}^{3} / \mathrm{s}\right)\end{array}$ & \multicolumn{2}{|c|}{ Main flume } & \multicolumn{2}{|c}{ Tributary flume } \\
\cline { 4 - 7 } & 0.053 & 0.122 & 1.0 & $2 \%$ & 0.4 & $2 \%$ \\
\hline 0.069 & & $\begin{array}{c}\text { Width } \\
(\mathrm{m})\end{array}$ & Slope & $\begin{array}{c}\text { Width } \\
(\mathrm{m})\end{array}$ & Slope \\
\hline
\end{tabular}

2.2. Setup and measurement of physical model experiments 
Two physical models were built for experimental tests in this study, which are defined as "Model \#1" and "Model \#2" respectively in this study for clarification. In the Model \#1, the model river confluence is designed to mimic the junction of the Baisha River and Shenxi River in Southwest China as shown in Fig. 3. In order to inspect the effect of tributary flow on the water level at river confluence in the main river, series of discharge scenarios from Baisha River and Shenxi River were performed in this physical model. A geometry normal scale of 20 (i.e., prototype scale: model scale = 20:1, defined as, $\lambda_{L}=20$ ) was chosen according to similar conditions in the prototype. Meanwhile, the ratio of model length and depth scales was also set at 20, and the discharge relation was supposed to be $\lambda_{Q}=\lambda_{L}{ }^{2.5}$ (i.e., $\lambda_{Q} / \lambda_{L}=1789$ ). A scenario of clear water experimental test with specified inflows from main and tributary rivers and the corresponding section arrangement of this physical model are shown in Fig. 3. The distance of $1.0 \mathrm{~m}$ between two adjacent sections reflects about $20 \mathrm{~m}$ in the prototype river. In total 8 experimental cases (termed as cases $1 \sim 8$ in this study) were conducted by considering two kinds of river inflows: one is from the main river only, the other is from both main and tributary rivers. The flow parameters are shown as Table 2 and Table 3, where the hydraulic conditions (e.g., Froude Number, Fr) are also provided in the tables.
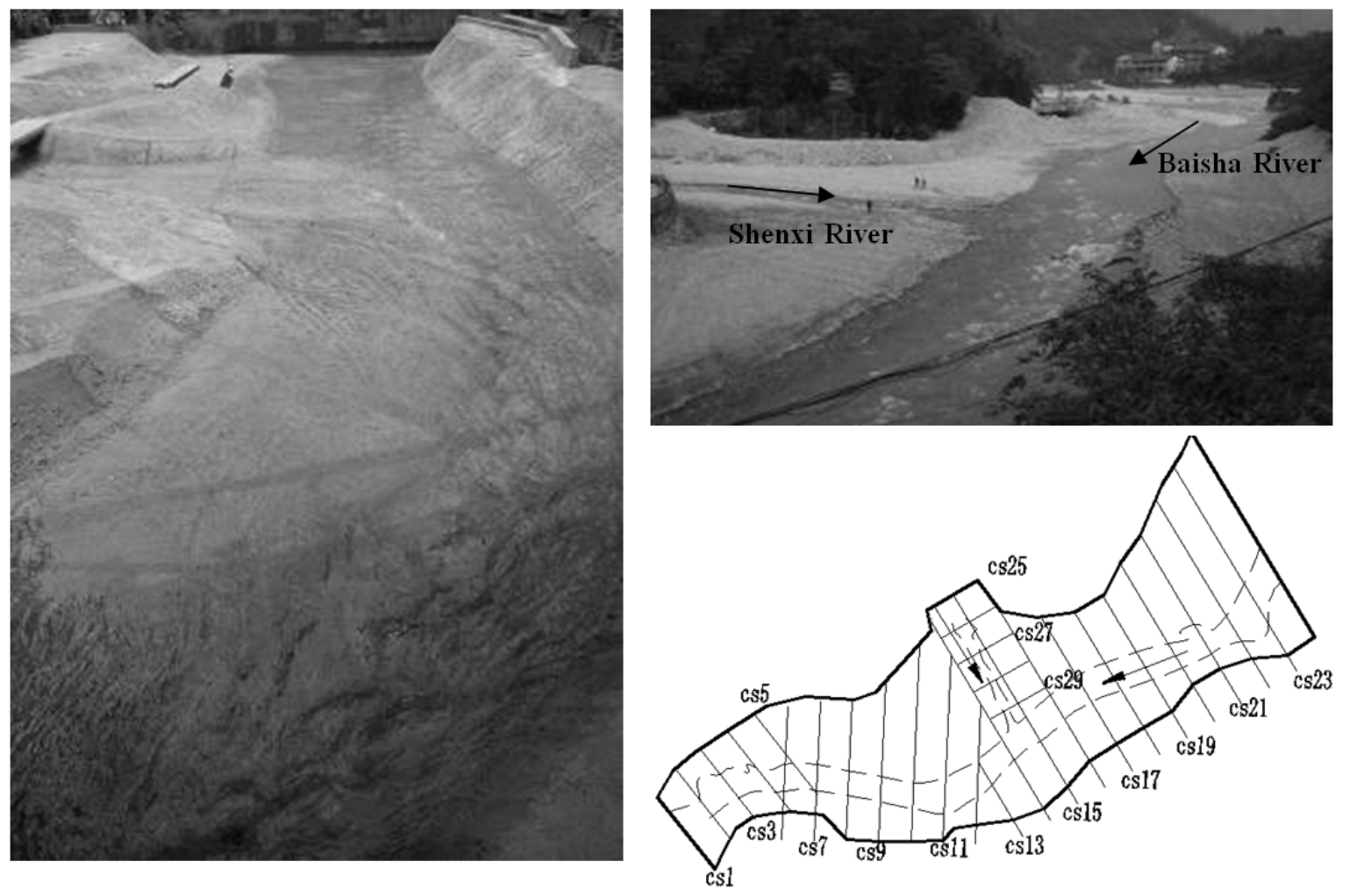

Figure 3. Model design and prototype photo of physical model \#1

Table 2. Experimental test cases of flow discharges in Baisha River

\begin{tabular}{c|c|c|c|c}
\hline Test case & 1 & 2 & 3 & 4 \\
\hline Prototype discharge $Q_{p}\left(\mathrm{~m}^{3} / \mathrm{s}\right)$ & 266.2 & 203.6 & 144.6 & 89.7 \\
Model discharge $Q_{m}\left(\mathrm{~m}^{3} / \mathrm{s}\right)$ & 0.149 & 0.114 & 0.081 & 0.050 \\
\hline
\end{tabular}

Table 3. Experimental test cases of flow discharges in Baisha River and Shenxi River 


\begin{tabular}{l|c|c|c|c|c}
\hline \multicolumn{2}{c|}{ Test case } & 5 & 6 & 7 & 8 \\
\hline \multirow{3}{*}{ Baisha River } & Prototype discharge $Q_{p}\left(\mathrm{~m}^{3} / \mathrm{s}\right)$ & 266.2 & 203.6 & 144.6 & 89.7 \\
& Model discharge $Q_{m}\left(\mathrm{~m}^{3} / \mathrm{s}\right)$ & 0.149 & 0.114 & 0.081 & 0.050 \\
\hline \multirow{2}{*}{ Shenxi River } & Prototype discharge $Q_{p}\left(\mathrm{~m}^{3} / \mathrm{s}\right)$ & 101.8 & 101.8 & 101.8 & 101.8 \\
& Model discharge $Q_{m}\left(\mathrm{~m}^{3} / \mathrm{s}\right)$ & 0.057 & 0.057 & 0.057 & 0.057 \\
\hline
\end{tabular}

The physical Model \#2 was built based on the prototype of the natural river confluence zone between Wahei River and Xianjiapu River in Sichuan Province of China, in which the Boluo water power station was built in February 1999 as shown in Fig. 4. On July 28, 2001, a serious rainfall event with a return period of 50 years resulted in the discharges of $Q_{w p}=1350 \mathrm{~m}^{3} / \mathrm{s}$ and $Q_{x p}=712 \mathrm{~m}^{3} / \mathrm{s}$ in the Wahei River and Xianjiapu River, respectively. As a result, a severe flooding disaster was occurred at the lower dyke reaches for the Boluo Power Station that was located at the confluence zone of the two rivers. For this consideration, the Model \#2 was constructed and tested to analyze flow characteristics and thus to understand the mechanisms and process of submerged flood disaster in the river confluence. In this model, the geometry normal scale of 50 (Prototype: Model=50:1, namely, $\lambda_{L}=50$ ), the plane (length and depth) model scale of 50, and the discharge relation of 17678 (i.e., $\lambda_{Q} / \lambda_{L}$ ) were applied.

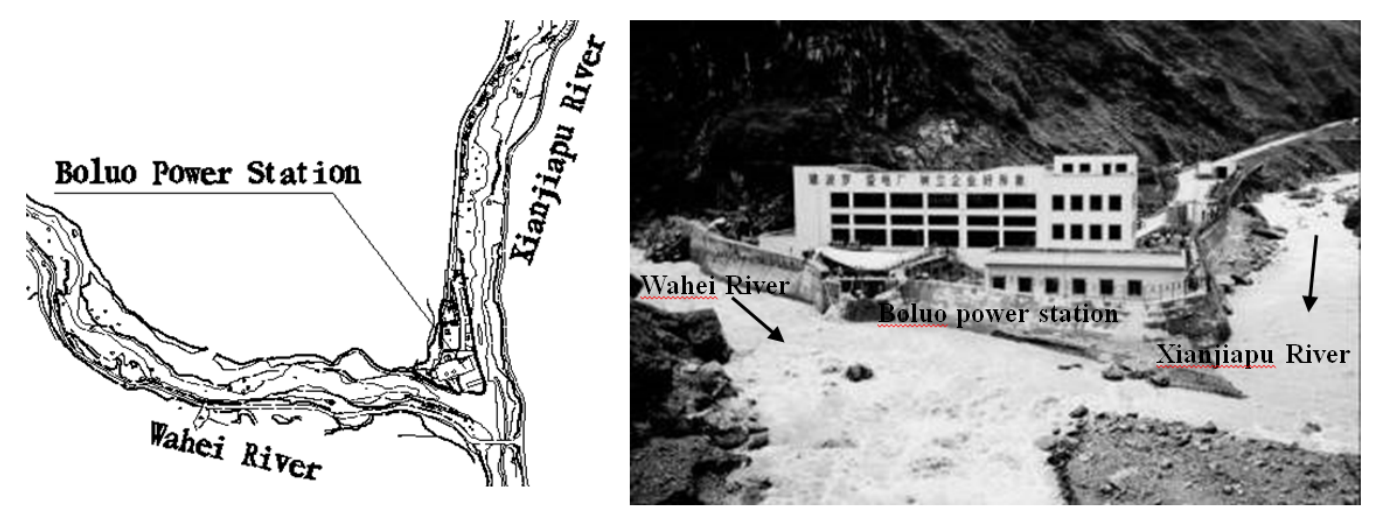

Figure 4. Sketch and photo of the river confluence zone between Wahei River and Xianjia River

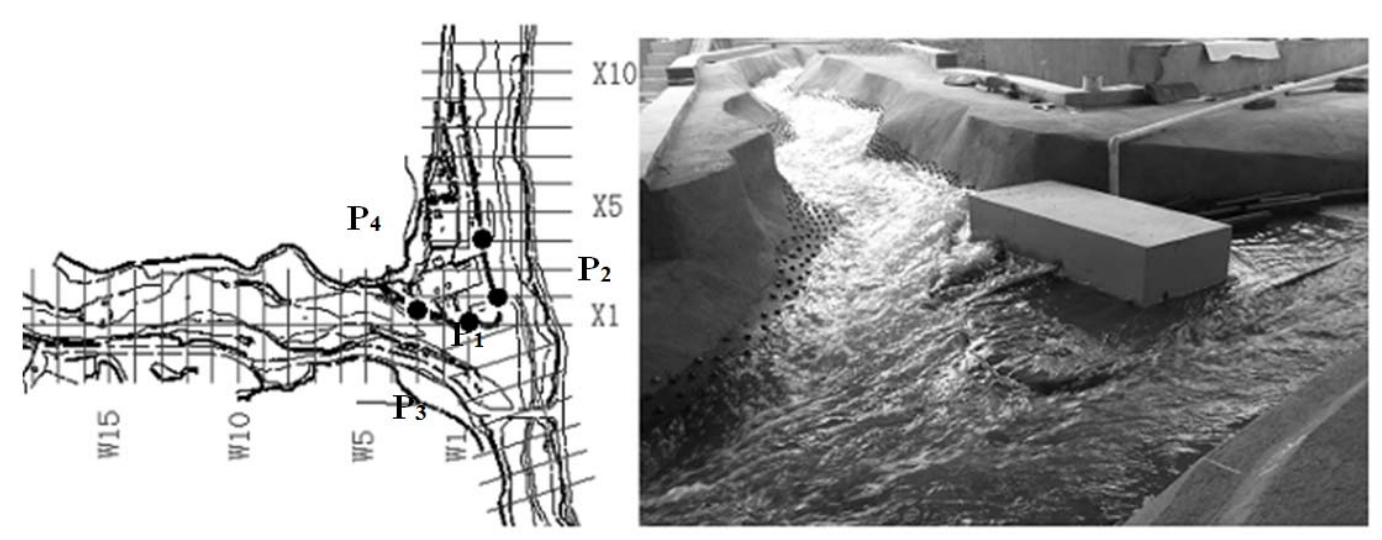

Figure 5. Measurement sections of physical model \#2 and experimental test scenario photo

Figure 5 shows the located sections and positions of this model for experimental measurement. In more details, four typical observational positions $\left(\boldsymbol{P}_{1}, \boldsymbol{P}_{2}, \boldsymbol{P}_{3}, \boldsymbol{P}_{4}\right)$ were designed to analyze the water 
level at the left bank of section 1 and section 3 in Wahei River and right bank of section 2 and section 4 in Xianjiapu River in order to compared with the relation between dyke elevation and water level elevation. The distance between two neighboring sections in this physical model is $50 \mathrm{~cm}$, which refers to $25 \mathrm{~m}$ in the prototype river according to the designed model geometry scale. Series of group flooding scenarios were carried out and tested in this experiment, with the experimental settings and parameters detailed in Table 4.

Table 4. Settings and parameters of experimental test groups in physical model \#2

\begin{tabular}{|c|c|c|c|c|c|c|}
\hline \multicolumn{2}{|r|}{ Test group } & Group 1 & Group 2 & Group 3 & Group 4 & Group 5 \\
\hline Wahei & $\begin{array}{l}\text { Prototype discharge } \\
\qquad Q_{w p}\left(\mathrm{~m}^{3} / \mathrm{s}\right)\end{array}$ & 554 & 1350 & 1220 & 1350 & 1540 \\
\hline River & $\begin{array}{l}\text { Model discharge } \\
Q_{w m}\left(\mathrm{~m}^{3} / \mathrm{s}\right)\end{array}$ & 0.031 & 0.076 & 0.069 & 0.076 & 0.087 \\
\hline Xianjiapu & $\begin{array}{l}\text { Prototype discharge } \\
\qquad Q_{x p}\left(\mathrm{~m}^{3} / \mathrm{s}\right)\end{array}$ & 159 & 712 & 796 & 886 & 1010 \\
\hline River & $\begin{array}{l}\text { Model discharge } \\
Q_{x m}\left(\mathrm{~m}^{3} / \mathrm{s}\right)\end{array}$ & 0.009 & 0.040 & 0.045 & 0.050 & 0.057 \\
\hline
\end{tabular}

\section{Results}

With the design and construction of different experimental programs above, extensive tests are conducted carefully and systematically for achieving the research objectives. The measurement results and analysis of each experiment are presented as follows.

\subsection{Results and analysis of flume experiments}

The two dimensional velocity vector fields in the $\mathrm{u}-\mathrm{v}$ plane are measured by above-mentioned equipment for different relative water depths defined by $Z^{*}=Z / B$ with $Z$ being measured water depth and $B$ the main flume width. The obtained results are plotted in Fig. 6, in which $Z^{*}=0.09,0.05$ and 0.018 represent for the positions near surface, middle layer and near bed regions respectively; $\mathrm{q}^{*}$ $(=Q / B)$ is defined as the discharge $(Q)$ per unit main flume width $(B)$. The results of velocity fields show clearly the sharp variations at different layers with the increase of water depth in confluence zone. More specifically, the water flow in main flume is forced and compressed (pushed and mixed) from the right to left bank at the confluence when the flow from tributary flume enters main flume at its right boundary with the angle $30^{\circ}$. This flow accumulation can thus result in an irregular and warped surface in the separation region at the downstream of the confluence junction and a lower water level in this region. Meanwhile, a backwater separation region is formed since the flow outside this region generates a contraction region leaning to the left boundary of the main channel flow. Moreover, a lower mean velocity in this section is shown in the contraction region and the upstream of confluence zone.

To confirm this result, Fig. 7 presents the contour of velocity field and water level at river confluence, which indicates clearly the flow structures and patterns including the separation region, higher and lower velocity regions and flow recovery regions. Compared with the shape and size of separation zone at different positions with different water depths in Figs. 6 and 7, the length and width of separation zone becomes gradually larger with the increase of water depth from the bed to water surface at the confluence, which is mainly due to the strong compression and accumulation from tributary flow at this section. This result confirms again the similar characteristics of the separation zone at the flow confluence observed and discussed in previous studies in this field (e.g., [15]). 


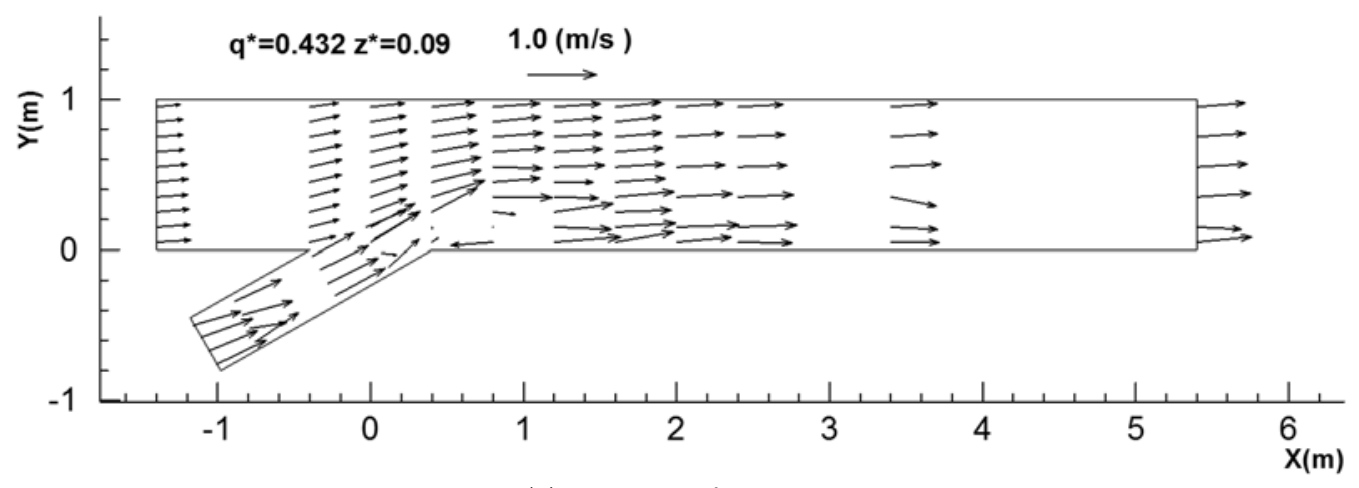

(a) Near surface $\left(Z^{*}=0.09\right)$

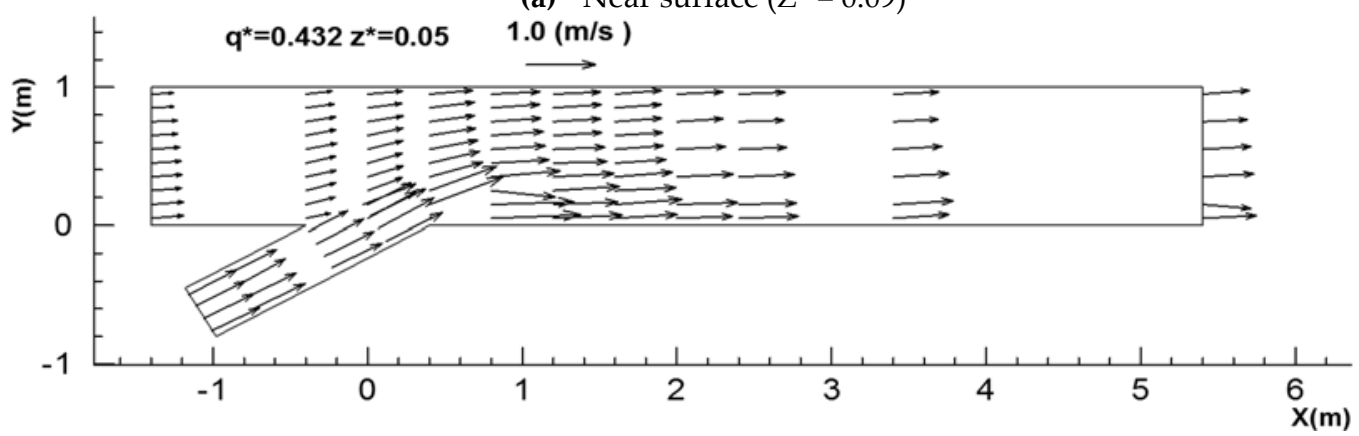

(b) Middle layer $\left(Z^{*}=0.05\right)$

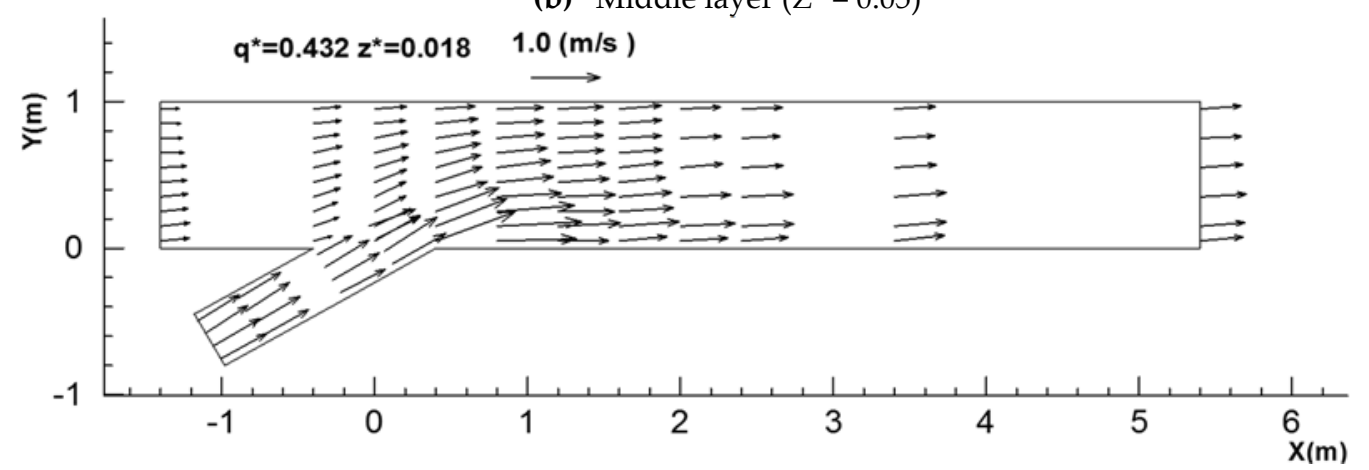

(c) Near bed $\left(Z^{*}=0.018\right)$

Figure 6. Measured u-v vector fields at the confluence zone in the flume experimental tests

To further study and understand the hydraulic characteristics of flows in the confluence zone, the velocity profiles over the vertical at different transverse positions (from Line $5 \#$ to Line 95\# shown in Fig. 2) are obtained and shown in Fig. 8. In total, there are 11 measurement sections located from the junction to the far downstream distance of the main channel are used for the analysis. By inspection, the results indicates that the transverse vertical velocity group may be divided into lower and higher velocity regions by means of flow shear plane in the whole confluence zone from section $\mathrm{m} 01$ \# to $\mathrm{mx} 07$ \# (see Fig. 2). The results also demonstrate that within the confluence zone, the range of the divided higher and lower velocity zones changes with the distance from the confluence junction, while after the confluence zone (e.g., at the section $\mathrm{mx} 08$ \#), the main flume flow starts to be extricated from the influence of junction flow confluence and the transverse vertical velocity profiles become close to uniform again. 

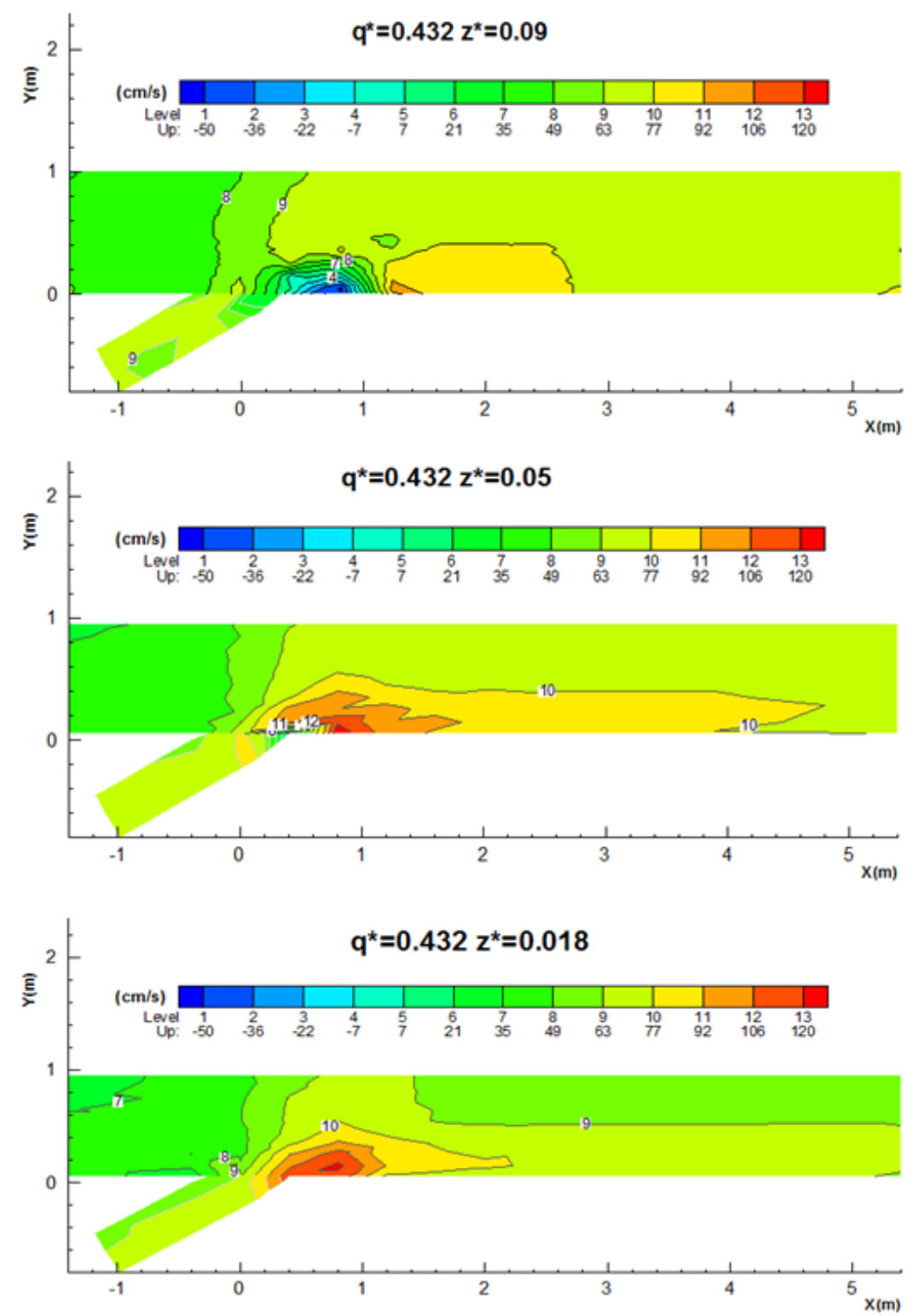

(a) Contour plots of measured velocity fields at near-surface, middle and near-bed locations

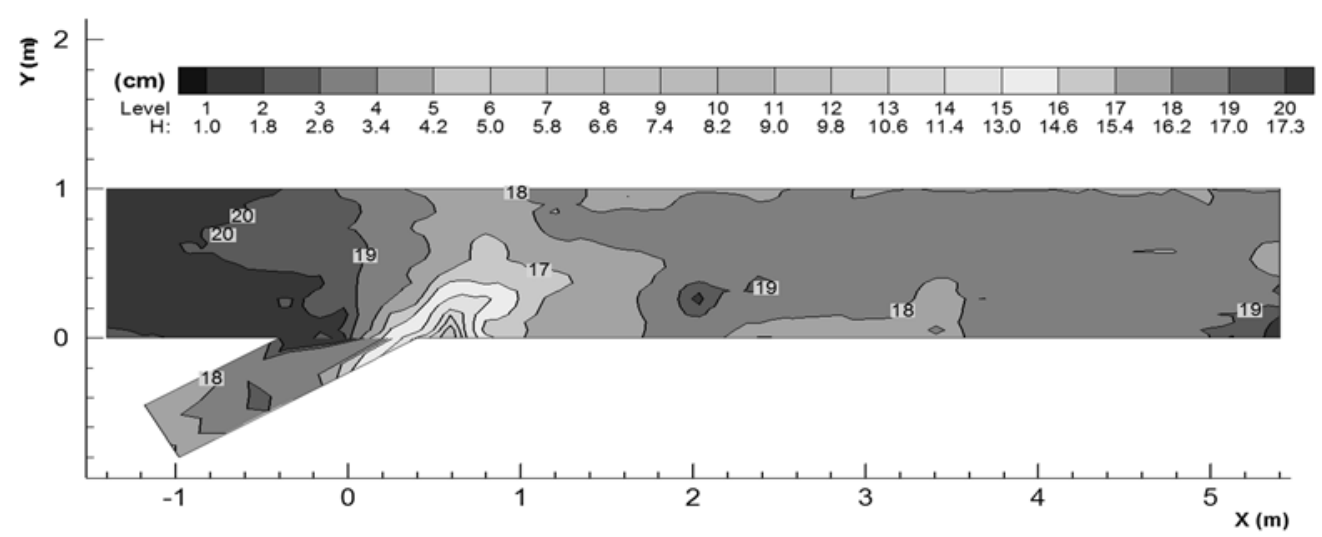

(b) Contour plot of measured water depth

Figure 7. Flow structures and patterns at the confluence zone in the flume experiment 


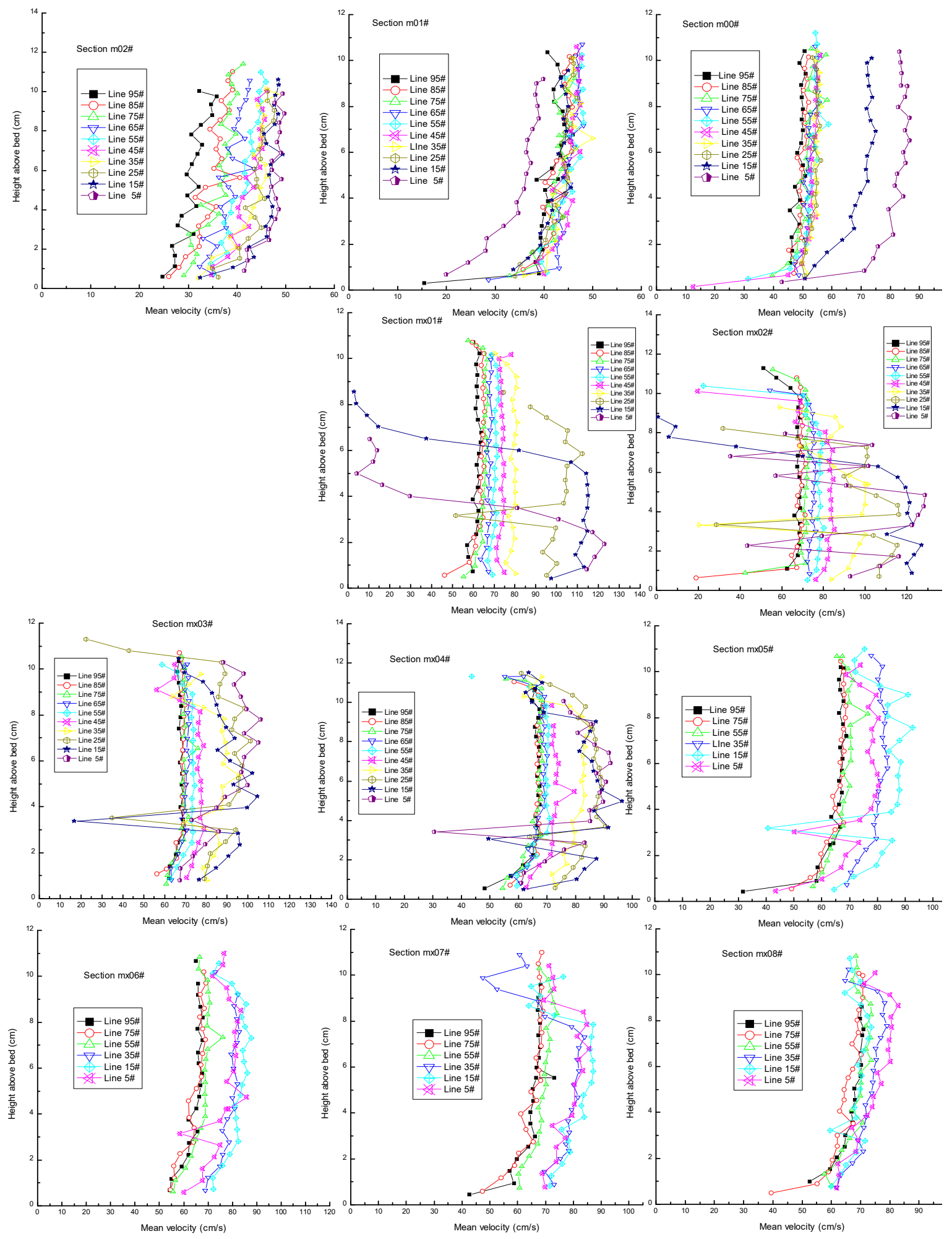

Figure 8. Mean vertical velocity distributions in the confluence zone

In the confluence region, the flow compression (pushing, mixing and accumulation) and backwater effects are resulted from the tributary flow confluence, and the mean velocity in the upper region at the same side of the tributary channel reduces abruptly. For example, the maximum on the Line $5 \#$ turned into minimum from section m02\# to section m01\#. On the contrary, the near right vertical velocity (Line $5 \#$ ) changes obviously from the minimum value at section m01\# to maximum value at section m00\# due to the flow compression and tributary inflow. In addition, the irregular changes of vertical velocity profiles with the transverse distance are resulted in an obvious separation 
zone (e.g., the results between Line $5 \#$ and Line $35 \#$ at section mx02\#). Particularly, in the upper section of the separation zone (e.g., at section m00\#), the velocity changes from Line 25\# to Line 95\# are much smaller than those in other two transverse locations in this section that are more close to the tributary side of the flume channel (Line $5 \#$ and Line 15\#). This is mainly due to strong flow mixing and compression-separation from the tributary flow confluence, which is explained in details later in this paper.

\subsection{Results and analysis of physical model \#1 experiments}
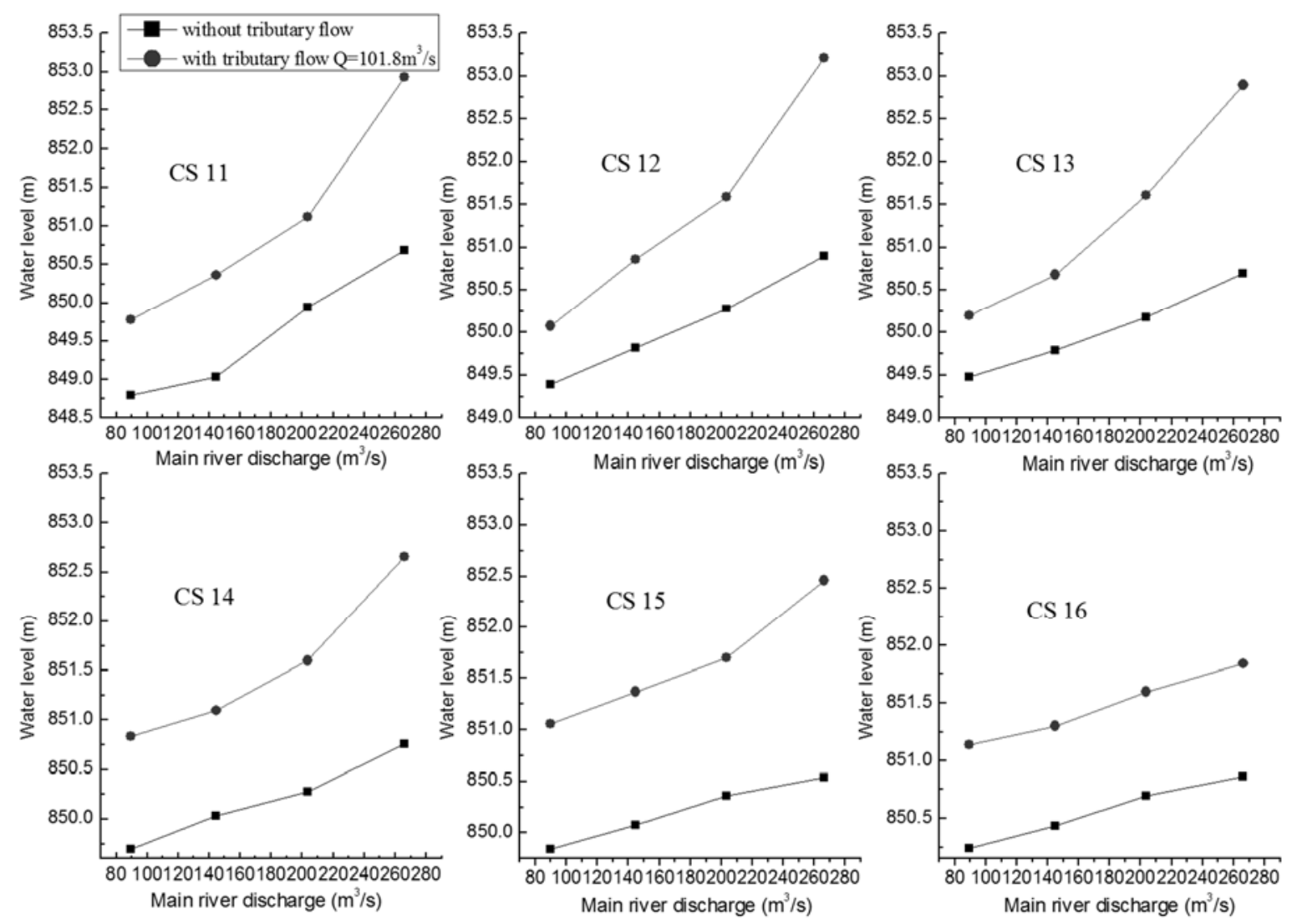

Figure 9. Measured stage-discharge relations at different sections for physical model \#1 with and without tributary flows

For the experimental tests of physical model \#1, Fig. 9 presents the changes of water level at selected measurement sections (i.e., CS $11 \sim$ CS 16 in Fig. 3) near the tributary entrance (located between section CS 14 and CS 15) with different inflow conditions at left bank of Baisha River. It is expected that the water level will increase with the enlarging discharge in the main channel, which has been confirmed by the experimental results here. On the one hand, under the condition of without tributary inflow (i.e., Shenxi River discharge is almost at $0 \mathrm{~m}^{3} / \mathrm{s}$ ), the water level of main channel increases gradually with the inflow of upper main stream for all measurement locations in Baisha River from $89.7 \mathrm{~m}^{3} / \mathrm{s}$ to $266.2 \mathrm{~m}^{3} / \mathrm{s}$ (i.e., from cases 4 to 1 in Table 2). On the other hand, under the condition that the inflow of the tributary river (Shenxi River) was increased to $101.8 \mathrm{~m}^{3} / \mathrm{s}$ (cases $5 \sim 8$ in Table 3), it is not surprise for the obtained results of the increased discharges and water levels at the downstream sections of confluence junction (i.e., CS 11 to CS 14). However, the results in Fig. 9 also reveal that the water levels at the upper stream of the confluence junction in the main river (e.g., CS 15 and CS 16) have also been raised. This is mainly due to the backwater effect of flow confluence action at the river junction, which is consistent with the hydrodynamic characteristics observed in the former flume experiments. Actually, the backwater characteristics can be further evidenced by the profile of the longitudinal water level changes as plotted in Fig. 10. The comparative results in Fig. 10 indicate an obvious decreasing trend of water levels at the upstream of the confluence junction 
between CS 17 and CS 15 under the condition of without tributary flows (cases 1 4), and on the contrary, an increasing trend of water levels at same locations due to the influence of the flow confluence from the tributary river (cases 5 8).

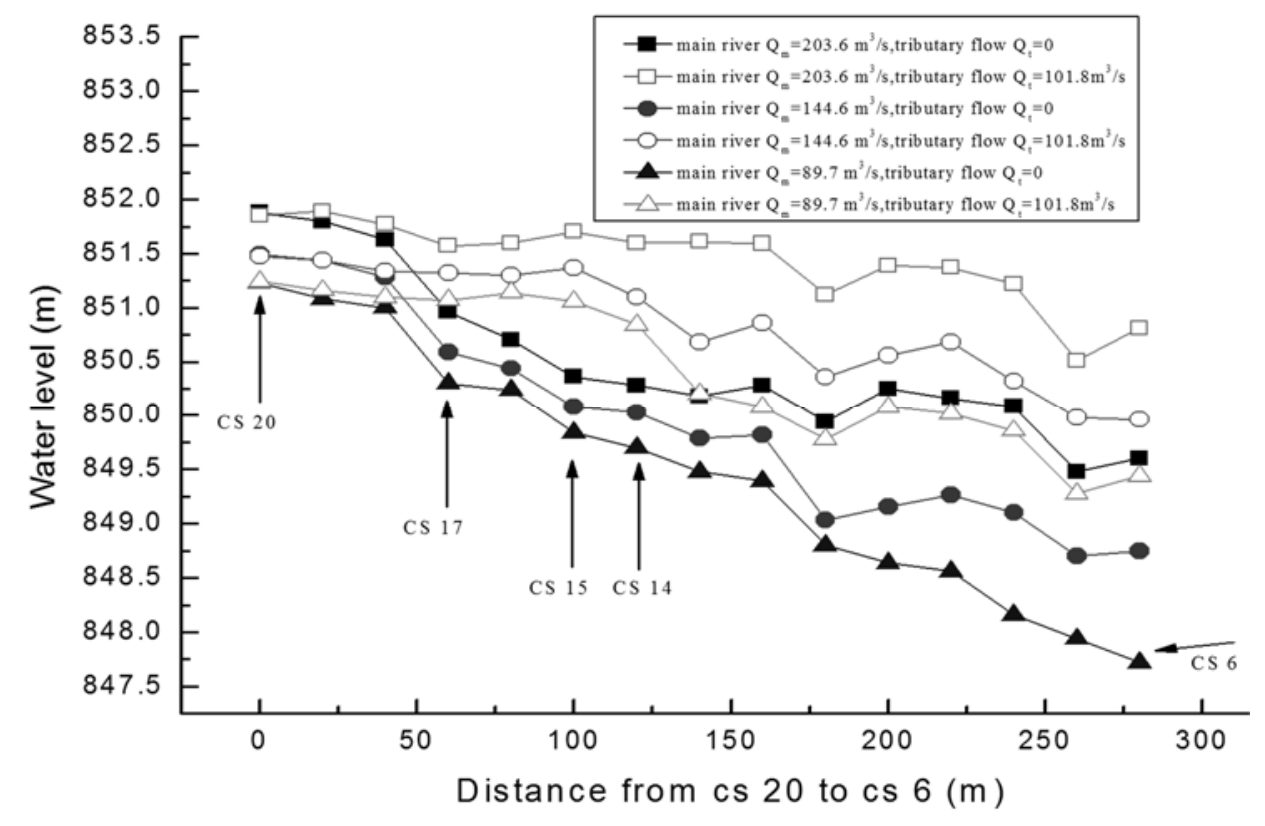

Figure 10. Longitudinal water level changes at the left bank of Baisha River for different inflows
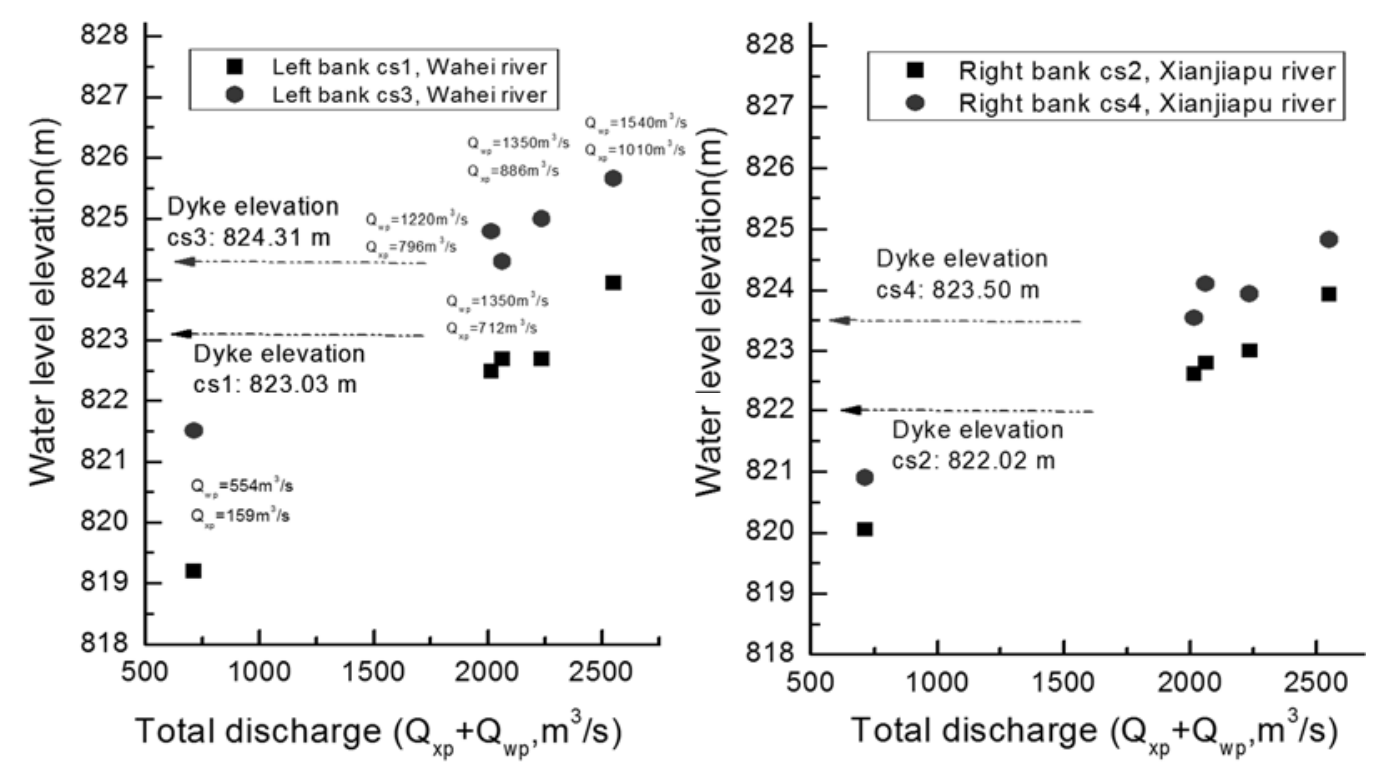

Figure 11. Measured stage-discharge relations for physical model \#2 with different inflows

\subsection{Results and analysis of physical model \#2 experiments}

Based on the experimental tests of physical model \#2, the stage-discharge results at the selected measurement positions (i.e., $\boldsymbol{P}_{1} \sim \boldsymbol{P}_{4}$ in Fig. 5) for a series of flooding test groups in Wahei River and Xianjiapu River are obtained and shown in Fig. 11. Meanwhile, the water surface levels and the dyke elevations at these positions are measured and given in Table 5. Specifically, the dyke elevations of the two positions $\left(\boldsymbol{P}_{1}, \boldsymbol{P}_{3}\right)$ are measured at $823.03 \mathrm{~m}$ and $824.31 \mathrm{~m}$ at the sections W1 and W3 on the left bank of Wahei River, and these of the other two positions $\left(\boldsymbol{P}_{2}, \boldsymbol{P}_{4}\right)$ are $822.02 \mathrm{~m}$ and $823.50 \mathrm{~m}$ at the sections $\boldsymbol{X}_{2}$ and $\boldsymbol{X}_{4}$ on the right bank of Xianjiapu River. At the same time, the results in Table 5 demonstrate that: (1) for the Wahei River, the dyke for flooding control at position $\boldsymbol{P}_{1}$ is submerged 
in the flood test group 5, and the water level elevation at position $P_{3}$ is mostly higher than the dyke elevation in the group 2 5, which induces easily flooding events; (2) for the Xianjiapu River, the dyke elevations are obviously lower than the water level elevation at both positions P2 and P4 in the flood test groups 2 5, and therefore, the flooding will likely occur for the Boluo Power Station under these drainage conditions (groups $2 \sim 5$ ). Consequently, the test results of the physical model \#2 imply that the current engineering project design (e.g., the dyke) in this river confluence region is not safe enough for the existing Boluo Power Station because of the high risks of flooding at this location.

Table 5. Measured elevations of the water level and dyke at the test positions

\begin{tabular}{|c|c|c|c|c|c|c|c|c|c|c|c|}
\hline \multirow{3}{*}{$\begin{array}{c}\text { Group } \\
\text { no. }\end{array}$} & \multicolumn{3}{|c|}{ Discharge $\left(\mathrm{m}^{3} / \mathrm{s}\right)$} & \multicolumn{8}{|c|}{ Elevation (m) } \\
\hline & \multirow[b]{2}{*}{$Q_{w p}$} & \multirow[b]{2}{*}{$Q_{x p}$} & \multirow{2}{*}{$\begin{array}{c}\text { QT } \\
\text { Total }\end{array}$} & \multicolumn{2}{|c|}{ P1 } & \multicolumn{2}{|c|}{ P3 } & \multicolumn{2}{|c|}{ P2 } & \multicolumn{2}{|c|}{$\mathrm{P} 4$} \\
\hline & & & & $\begin{array}{c}\text { Water } \\
\text { level }\end{array}$ & Dyke & $\begin{array}{c}\text { Water } \\
\text { level }\end{array}$ & Dyke & $\begin{array}{c}\text { Water } \\
\text { level }\end{array}$ & Dyke & $\begin{array}{c}\text { Water } \\
\text { level }\end{array}$ & Dyke \\
\hline 1 & 554 & 159 & 713 & 819.2 & & 821.5 & & 820.1 & & 820.9 & \\
\hline 2 & 1220 & 796 & 2016 & 822.5 & & 824.8 & & 822.6 & & 823.5 & \\
\hline 3 & 1350 & 712 & 2062 & 822.7 & 823.0 & 824.3 & 824.3 & 822.8 & 822.0 & 824.1 & 823.5 \\
\hline 4 & 1350 & 886 & 2236 & 822.7 & & 825.0 & & 823.0 & & 823.9 & \\
\hline 5 & 1540 & 1010 & 2550 & 824.0 & & 825.7 & & 823.9 & & 824.8 & \\
\hline
\end{tabular}

\section{Discussion}

The above results and analysis of extensive experimental tests in this study have demonstrated clearly the important influence of the flow junction to the flow characteristics and process at the river confluence. On the basis of these observations and findings, it is necessary to understand further and investigate systematically the physical mechanisms and change process of flow structures and stagedischarge relationship at the confluence. For this purpose, the qualitative and quantitative analyses are performed for the obtained results in this section.

\subsection{Hydraulic characteristics of flow structures at river confluence}

For the single channel flow with a fixed and steady discharge, it is known that the water level at specified locations increases with the decrease of flow velocity. However this characteristic may not be exactly true for the complex channel with flow confluences, such as the situations tested in this study. Particularly, the former analysis of Fig. 7 has demonstrated the two regions of relatively lower and higher velocities and the occurrence of backwater in the confluence zone. In order to explain such characteristics of junction flow, the water levels of several typical transverse and longitudinal sections are plotted in Figs. 12(a) and 12(b) respectively for the flume experimental tests at different locations and sections along the channel. By inspection, the results reveal that the water levels at sections m02\#, $\mathrm{m} 01 \#$ and $\mathrm{mx} 00 \#$ are almost the same due to the existence of backwater effect, which is, however, larger than the value at $\mathrm{mx} 04$ \# section at the downstream separation zone. Meanwhile, it is found that the water level at mx01\# section that is close to the left bank is also much higher than that in the separation zone as shown in Fig. 12(b). This is mainly due to the lateral momentum transfer effect from the tributary flow to the main stream flow at the confluence zone, so that strong mixing shear layers and secondary flows were formed in this region, which has also been widely observed and examined in previous theoretical and experimental studies (e.g., [2, 3, 14, 15]).

Meanwhile, the 2D and 3D characteristics of the mixing flows (i.e., spatial and temporal variations and distributions of velocity and water depth) in the confluence junction and the downstream zone are clearly observed in Fig. 7, which is consistent with the findings of previous studies about the mixing shear layers. However, because of the angled confluence flows at river junctions considered in this study, the mixing shear layers (e.g., thickness and evolution) in these 
experimental tests could not be well represented and accurately predicted by the proposed theory and formulas in the previous studies (e.g., $[3,21])$ in which the parallel inflows were usually assumed. Actually, the evolution of the mixing shear layers in the angled confluence flows was found to be much more non-linear (and thus more complicated) than that in the parallel and uniform open channel systems. From this perspective, the experimental tests and measurement results of this study may be useful to the extension and analysis of the current mixing shear layer theory in the future work.

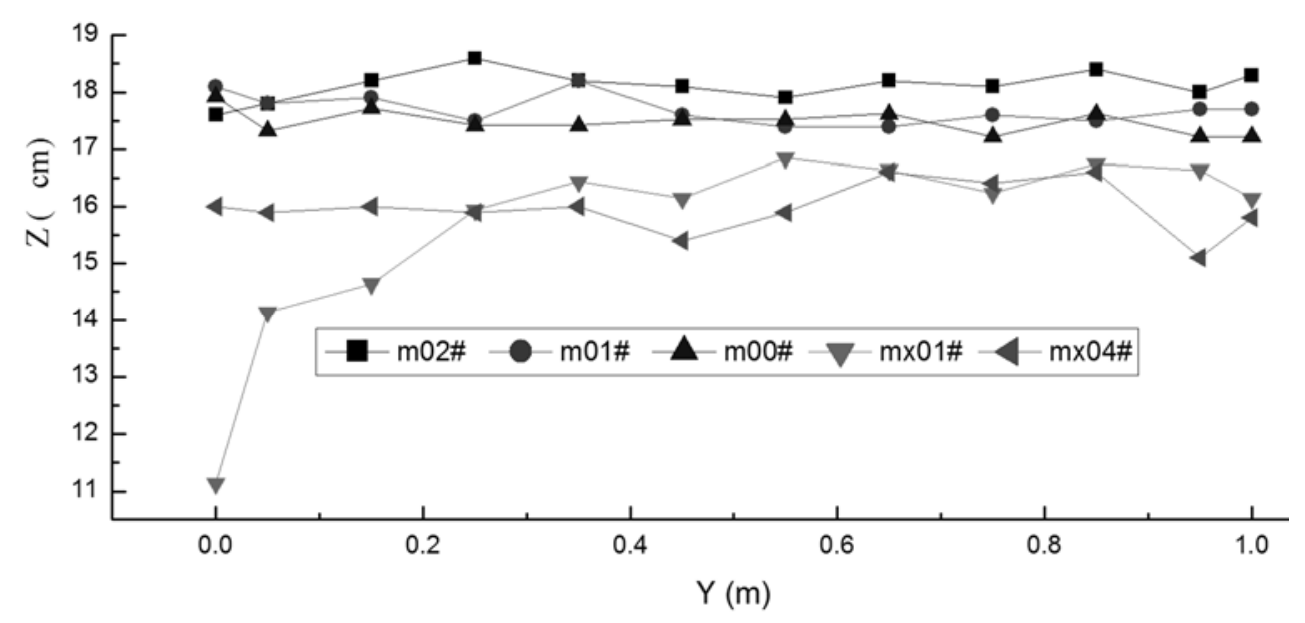

(a) Variation of transverse water level at five typical sections

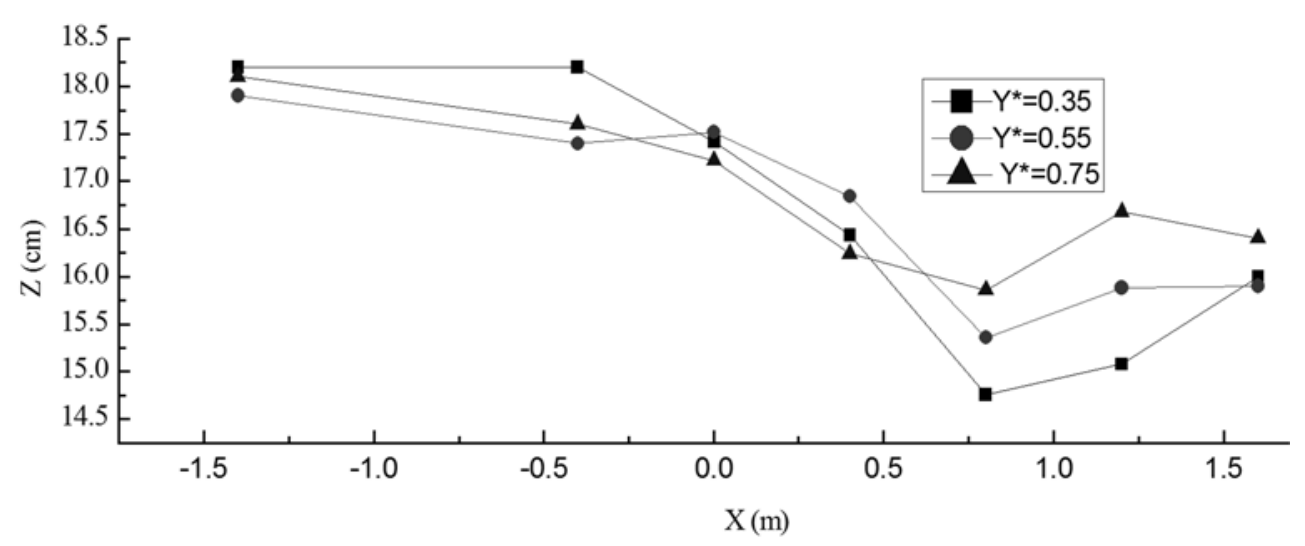

(b) Variation of longitudinal water level at typical positions from sections m02 \# to mx04 \#

Figure 12. Characteristics of water level variations in the confluence zone

Consequently, these test results and analysis imply clearly the complex variations of water levels in the river channel with flow confluences, which therefore may have great impact on the stagedischarge relationship at flow junctions. Such influence to the stage-discharge relationship is discussed in details in the following part of the paper.

\subsection{Assessment and analysis of stage-discharge relationship at river confluences}

As reviewed in the former introduction part of this study, many previous studies have focused on the development and analysis of the stage-discharge relationship in complex open channels. Particularly, the composite and compound open channels were commonly considered in these studies and relevant theories and formulas have been proposed and applied to predict the discharges at such channel systems (e.g., [28, 30 and 31]). Therefore, it is worthwhile to examine and discuss the validity of current theory for the complex situations, in order to provide useful foundation and valuable suggestions on its extension and development. 
In this section, the theoretical/empirical stage-discharge relationship in the literature is compared with the experimental data in this study so as to examine its validity and accuracy. For illustration, the commonly used Chézy formula for steady or quasi-steady flows is adopted for the analysis, and defined as ([32]),

$$
Q=A V=A C\left(R S_{f}\right)^{0.5},
$$

where $A$ is the flow cross sectional area, $V$ is the mean cross sectional velocity, $R$ is the hydraulic radius, $\mathrm{Sf}$ is the frictional slope, $C$ is the Chézy coefficient that can be calculated by Manning friction coefficient as $C=R{ }^{16} / n$, with $\mathrm{n}$ being roughness coefficient relating to the channel characteristics. The frictional slop $S_{f}$ can be approximated by following equation, which is derived from the steady-state based one-dimensional (1D) St. Venant momentum equation ([32]),

$$
S_{f}=\underbrace{S_{0}}_{\text {uniform term }}-\underbrace{\frac{Q^{2}}{g A} \frac{\partial}{\partial x}\left(\frac{1}{A}\right)-\frac{\partial h}{\partial x}}_{\text {non-uniform term }},
$$

in which the first term on the right hand side (RHS) of the equation is attributed to the uniform flow part, while the rest terms of the RHS represent the non-uniformity of the flow along the channel. Based on this theoretical discharge-stage formula, the laboratory experiment tests and field measurement are examined respectively for the comparative analysis. The results are shown in Figs. 13 and 14, where the discharge of the vertical coordinates is normalized by the total discharge $\left(Q_{T}\right)$ after the confluence.

Figure 13 illustrates the result comparison of the laboratory experiment flume between the predicated and measured discharges in the main channel. Note that the results of $Q_{c}$ and $Q_{c r}$ refer to the predicted discharges based on the frictional slope by the uniform part only and both uniform and non-uniform parts in Eq. (2), in order to highlight the importance and influence of the non-uniformity of the confluence flows. On the one hand, the results of Fig. 13 show that the both numerical predictions are agreed well with the measured data for the upstream channel flow, which indicates the little influence of the non-uniformity of the confluence flows to the current stage-discharge relationship of the upstream channel. On the other hand, clear discrepancies of such comparison are observed for the downstream channel flow, which implies the significant impacts of the confluences on this 1D theoretical stage-discharge relationship. Particularly, the river confluences can result in remarkable non-uniformity of the downstream discharge in the confluence zone. Meanwhile, complex flow structures of the confluence flows may have great influences to the validity of this theoretical stage-discharge relationship which was originally derived from 1D averaged momentum principle. Therefore, from this comparative analysis, it is necessary to develop and apply nonuniform based multi-dimensional relations to represent accurately the stage-discharge relationship in the channel confluence zone.

This conclusion for the laboratory experiment flume is also confirmed by the comparative results of the test cases (no. 6 and no. 8 in Table 3) for the field study system as plotted in Fig. 14. Firstly, the river confluence has less influence of the stage-discharge relationship to the upstream river sections than that to the river downstream. However, influence to the upstream flow is clearly larger than that in the former laboratory experiment system (e.g., sections cs $15 \sim$ cs 16 in Fig. 14). This is mainly because of the more significant backwater effect resulted in this field system. Furthermore, the remarkable discrepancies between the prediction and measurement are also observed for the downstream discharges in this field system, which evidences the important influences of the confluences to the downstream flow structure and stage-discharge relationship. Nevertheless, it is also found that this discrepancy is very case-dependent, that is, the discharge is overestimated in case no. 6 , and underestimated in case no. 8. This different variation trend may be attributed to the different discharge ratios of the mainstream and tributary in these two cases (case no. 6: 2.01; and case no. 8: 0.88). Specifically, a smaller mainstream-tributary discharge ratio, e.g., in case no. 8 with the ratio $<1$, means the more dominant inflow from the tributary to the total discharge at the downstream of the confluence, so that more complex and prominent flow structure of separation effect resulted from the strong mixing and compression as well as the momentum change between 
the tributary and the mainstream. Under the influence of this complex flow separation structure, the discharge may be underestimated by the current $1 \mathrm{D}$ averaged stage-discharge relationship. On the contrary, when the mainstream-tributary discharge ratio becomes larger (e.g., case no. 6 here with ratio $>1$ ), the flow accumulation effect will be more dominant than the separation effect, and therefore, an opposite variation trend of the prediction discrepancy by this current stage-discharge relationship can be observed in Fig. 14.

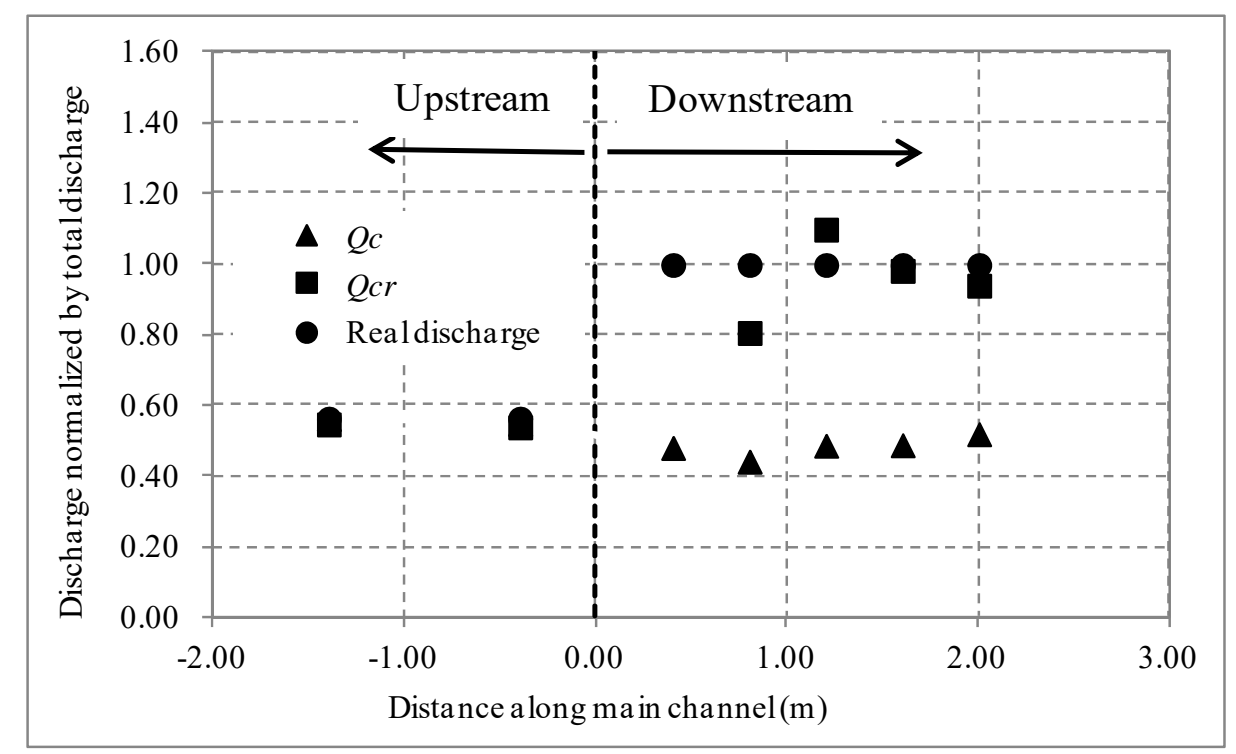

Figure 13. Comparison of measured and predicted stage-discharge relations for the laboratory experiment flume

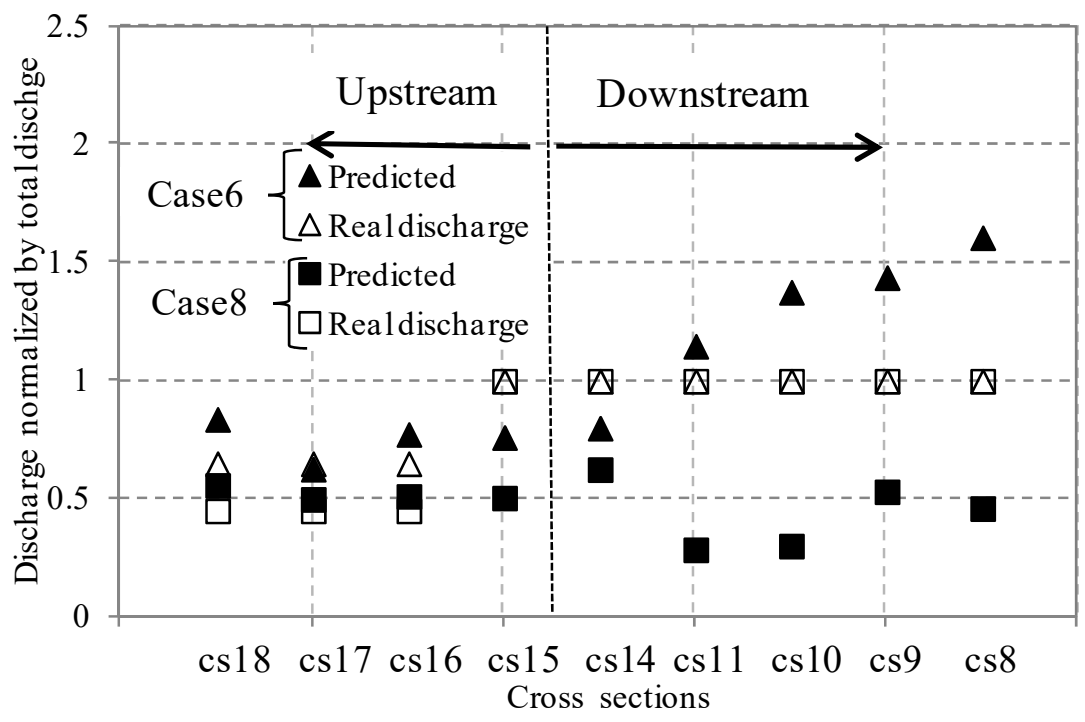

Figure 14. Comparison of measured and predicted stage-discharge relations for the field study system

Consequently, through the above comparison and analysis, it can be concluded that the river confluence may have significant influences to the stage-discharge relationship due to the complex flow structures (backwater and separation) resulted from the confluence flows. In this regard, it is suggested that the complex hydrodynamics and non-uniform flow structures of the river confluences are needed to be considered and included in the development of the stage-discharge relationship for mountain river flows. 


\subsection{Scientific and practical implications}

With above analysis and discussion, it can be concluded that the river confluence has great influence to the hydraulic characteristics and stage-discharge relationship of open channel flows. Extensive experimental tests and results indicate clearly the non-uniformity of flow structures and patterns at the confluence zone including the upstream and downstream of the river confluence junction, which causes the profound discrepancy and inaccuracy of traditional stage-discharge relationships to represent and predict the flow capacity along the angled confluence channel. From this point of view, an in-depth understanding of the characteristics of river confluence flows is necessary, so that more physical and appropriate theory for describing the complex confluence flow structure and pattern. From this perspective, the detailed data measurement of velocity and water level distributions may be usable to this theoretical development for the future work.

Furthermore, from the perspective of practical engineering design and management, mountain river flooding issue has become more and more severe, which may also result in various subsequent disasters such as debris and landslip in the mountain resident area. Based on the results and analysis of this study, the flooding risk was usually underestimated by applying the traditional and common design and management methods (e.g., the current stage-discharge relationships). This underestimated risk has been evidenced through a practical engineering project of the Boluo Power Station in the mountain are of Southwest China (see Fig. 4). Consequently, on the basis of this study, the extension and further development of more accurate and general stage-discharge relationships with including the influence of river confluence will be greatly beneficial to the practical river engineering.

\section{Conclusions}

This paper investigates the characteristics of flow structures and stage-discharge relationships in river confluence zone based on abundant experimental program including laboratory flume tests and physical model applications. The velocity and water level fields were firstly measured in details from the flume experiments. The results and analysis show clearly the influence of flow confluences on the velocity distribution, where the low and high velocity regions can be divided at the river confluence. Meanwhile, the effects of flow confluences on the backwater and flow separation characteristics at the channel junction are discussed based on the obtained data. The results confirm the findings of complex hydrodynamic characteristics at river confluences in previous studies.

Furthermore, two physical model experiments were designed with hydraulic similarities of the relevant prototypes of river confluence systems in Southwest China, with test results for extending and verifying the laboratory flume experiments and examining the impacts of flow confluences on the flooding control and risk evaluation. The result analysis demonstrates the potential influence of tributary river inflows to the water levels and flow structures at the confluence region, and flooding risk may be highly increased by the confluence flows at the junction region. Particularly, the model test results indicate that the flooding risk has been underestimated for the existing Boluo Power Station in this river confluence zone between Wahei River and Xianjiapu River, and suggests the engineering project improvement (e.g., dyke elevation) at this critical location.

With the extensive test results gained in this study, the commonly used stage-discharge relationship is evaluated and quantified for the situations of river confluence through comparative analysis, and the inaccuracy is interpreted from the physical understanding and hydrodynamics in this study. The theoretical and practical implications of the results and findings to the river hydraulics and engineering are discussed in the paper.

Acknowledgments: All sources of funding of the study should be disclosed. Please clearly indicate grants that you have received in support of your research work. Clearly state if you received funds for covering the costs to publish in open access. The work was partially supported by: (1) the Science and Technology support program of Sichuan Province, China (Grant No. 2014SZ0163); (2) the National Natural Science Foundation of China (Grant No. 51579163); (3) the Open Foundation of State Key Laboratory of Hydraulics and Mountain River Engineering Sichuan University (Grant No. SKHL1417); and (4) the Hong Kong Research Grant Council (Grant No. 25200616). The authors would also like to thank the graduate students and technical staffs in the State Key Laboratory of 
Hydraulics and Mountain River Engineering Sichuan University for their kind help in the experiments of this study.

Author Contributions: In the achievement of this work, the author contributions are as follows: Xiekang Wang and Haizhou Wang conceived and designed the experiments; Haizhou Wang and Xufeng Yanperformed the experiments; Xufeng Yan, Haizhou Wang and Huan-Feng Duan analyzed the data; Xiekang Wang and HuanFeng Duan contributed reagents/materials/analysis tools; Xufeng Yan and Huan-Feng Duan wrote the paper.

Conflicts of Interest: The authors declare no conflict of interest.

\section{References}

1. Dai, F.C.; Lee, C.F.; Deng, J.H.; Tham, L.G. The 1786 earthquake-triggered landslide dam and subsequent dam-break flood on the Dadu River, Southwest China. Geomorphology 2005, 65(3-4), 205-221.

2. Rhoads, B.L.; Sukhodolov, A.N. Spatial and temporal structure of shear layer turbulence at a stream confluence. Water Resources Research 2004, 40, W06304, doi:10.1029/2003WR002811.

3. Sukhodolov, A.N.; Schnauder, I.; Uijttewaal W.S.J. Dynamics of shallow lateral shear layers: Experimental study in a river with a sandy bed. Water Resources Research 2010, 46, W11519, doi:10.1029/2010WR009245.

4. Zhou, S.F. Study on Flow Pattern and Disaster Reduction Method in River Confluences. Master Degree Thesis, the State Key Laboratory of Hydraulics and Mountain River Engineering, Sichuan University, China, 2014.

5. Taylor, E.H. Flow characteristics at rectangular open channel junction. Trans ASCE 1944, 109, 893-902.

6. Webber, N.B.; Greated, C.A. An investigation of flow behavior at the junction of rectangle channels. Proc. Inst. Civ. Eng., Thomas Telford Ltd., London, 1996, 34, 321-334.

7. Best, J.L.; Reid, I. Separation zone at open-channel junctions. Journal of Hydraulic Engineering ASCE 1984, 110(11), 1588-1594.

8. Đorđević, D. Numerical study of 3D flow at right-angled confluences with and without upstream planform curvature. Journal of Hydroinformatics, 2013, 15(4), 1073-1088, doi: 10.2166/hydro.2012.150.

9. Weber, L.J.; Eric, D.S.; Nicola, M. Experiments on Flow at a $90^{\circ}$ Open-Channel Junction. Journal of Hydraulic Engineering ASCE 2001, 127(5), 340-350.

10. Rhoads, B.L.; Kenworthy, S.T. Time-averaged flow structure in the central region of a stream confluence. Earth Surface Processes and Landforms 1998, 23, 171-191.

11. Bradbrook, K.F.; Lane, S.N.; Richards, K.S. Numerical simulation of three-dimensional, time-averaged flow structure at river channel confluences. Water Resources Research 2000, 36(9), 2731-2746.

12. Liu, T.H. Experimental Study on Hydrodynamic Characteristics and Sediment Motion at Mountain Confluent River. Master Degree Thesis, State Key Laboratory of Hydraulics and Mountain River Engineering, Sichuan University, China, 2005.

13. Parsons, D.R.; Best, J.L.; Lane, S.N.; Orfeo, O.; Hardy, R.J.; Kostaschuk, R. Form roughness and the absence of secondary flow in a large confluence-diffluence, Rio Paraná, Argentina. Earth Surface Processes and Landforms 2007, 32, 155-162.

14. Wang, X.K.; Yang, Q.Y.; Lu, W.Z.; Sun, Y. Study on characteristics of separation zone in confluence river. Journal of Sichuan University (Engineering Science Edition) (in Chinese), 2008, 40(6), 1-6.

15. Yang, Q.Y.; Wang, X.Y.; Lu, W.Z.; Wang, X.K. Experimental study on characteristics of separation zone in confluence zones in rivers. Journal of Hydrological Engineering ASCE 2009, 14(2), 166-171.

16. Yang, Q.Y.; Sun, Y.; Wang, X.Y.; Lu, W.Z.; Wang, X.K. Effects of turbulence models on the numerical simulation of flow in open channel confluence. Mechanics of Advanced Materials and Structures 2011, 18(6), 566-571.

17. Mianaei, S.J.; Keshavarzi, A.R. Study of near bed stochastic turbulence and sediment entrainment over the ripples at the bed of open channel using image processing technique. Stochastic Environmental Research and Risk Assessment 2010, 24, 591-598.

18. Shakibainia, A.; Tabatabai, M.R.; Zarrat, A.R. Three-dimensional numerical study of flow structure in channel confluences. Canadian Journal of Civil Engineering 2010, 37, 772-781.

19. Riley, J.D.; Rhoads, B.L. Flow structure and channel morphology at a natural confluent meander bend. Geomorphology 2012, 163-164, 84-98

20. Zhou, S.F.; Ye, L.; Liu, X.N.; Wang, X.K. Study on the backwater effects on flow characteristics at confluence zone between Jialing River and Yangtze River (in Chinese). Journal of Sichuan University (Engineering Science Edition) 2014, 46(supp.1), 7-11. 
21. Best, J.L.; Roy, A.G. Mixing-layer distortion at the confluence of channels of different depth. Nature 1991, 350, 411-413.

22. Biron, P.; Best, J.L.; Roy, A.G. Effects of bed discordance on flow dynamics at open channel confluences. Journal of Hydraulic Engineering ASCE 1996, 122(12), 676-682.

23. Rhoads, B.L.; Sukhodolov, A.N. Field investigation of three-dimensional flow structure at stream confluences: 1. Thermal mixing and time-averaged velocities. Water Resources Research 2001, 37(9), 2393 2410.

24. Rhoads, B.L.; Sukhodolov, A.N. Field investigation of three-dimensional flow structure at stream confluences: 2. Turbulence. Water Resources Research 2001, 37(9), 2411-2424.

25. Yang, Q.Y.; Lu, W.Z.; Zhou, S.F.; Wang, X.K. Impact of dissipation and dispersion terms on simulations of open-channel confluence flow using two-dimensional depth-averaged model. Hydrological Processes 2014, 28, 3230-3240.

26. He, H.M.; Zhou, J.; Yu, Q.; Tian, Y.Q.; Chen, R.F. Flood frequency and routing processes at a confluence of the middle Yellow River in China. River Research and Applications 2007, 23, 407-427.

27. Roca, M.; Martín-Vide, J.P.; Moreta, P.J.M. Modelling a torrential event in a river confluence. Journal of Hydrology 2009, 364, 207-215.

28. Khatua, K.K.; Patra, K.C.; Mohanty, P.K. Stage-discharge prediction for straight and smooth compound channels with wide floodplains. Journal of Hydraulic Engineering ASCE 2012, 138(1), 93-99.

29. Wilson, C.A.M.E.; Bates, P.D.; Hervouet, J.M. Comparison of turbulence models for stage-discharge rating curve prediction in reach-scale compound channel flows using two-dimensional finite element methods. Journal of Hydrology 2002, 257, 42-58.

30. Liao, H.S.; Knight, D.W. Analytic stage-discharge formulas for flow in straight prismatic channels. Journal of Hydraulic Engineering ASCE 2007, 133(10), 1111-1122.

31. Kean, J.W.; Smith, J.D. Calculation of stage-discharge relationships for gravel bedded channels. Journal of Geophysical Research 2010, 115, F03020, doi:10.1029/2009JF001398.

32. Schmidt, A.R.; Yen, B.C. Stage-discharge relationship in open channels. Proceedings of the 3rd International Symposium on Environmental Hydraulics, ISEH and IAHR, Tempe, Arizona, USA, 5-8 December 2001.

(C) 2016 by the authors; licensee Preprints, Basel, Switzerland. This article is an open access article distributed under the terms and conditions of the Creative Commons by Attribution (CC-BY) license (http://creativecommons.org/licenses/by/4.0/). 